\author{
А.Д. Шмелев \\ Институт русского языка им. В. В. Виноградова РАН \\ Московский педагогический государственныий университет \\ Православный Свято-Тихоновский гуманитарный университет (Россия, Москва) \\ shmelev.alexei@gmail.com
}

\title{
ЕЩЕ РАЗ О ГОРДОСТИ В ИСТОРИИ РУССКОГО ЯЗЫКА И РУССКОЙ КУЛЬТУРЫ: ОТ «ДЕМОНСКОЙ ТВЕРДЫНИ» К ЧУВСТВУ СОБСТВЕННОГО ДОСТОИНСТВА
}

В статье делается попытка проследить историю языковых выражений, соотносимых с понятием «гордость», на протяжении последних двух веков, а также установить связь этих изменений с перестройкой русской языковой картины мира. В русской языковой картине мира, как и в картинах мира многих других языков, сформированных под влиянием традиционной христианской этики, гордость в течение долгого времени понималась как общая жизненная установка, состоящая в чрезмерно и необоснованно высоком мнении о самом себе, часто сочетающемся с презрением по отношению к другим. Это понимание в значительной мере определялось христианской этикой, в которой гордость считалась первым из смертных грехов и противопоставлялась смирению. Постепенно, в процессе секуляризации общества, а также в связи с распространением романтических настроений, понятие «гордость» стало переосмысляться. Гордость стала пониматься как чувство человека, который думает, что с ним связано нечто хорошее, из-за чего другие люди будут думать о нем лучше, а в качестве общей жизненной установки гордость стала восприниматься как нечто близкое «чувству собственного достоинства». Рассмотренные семантические сдвиги отражают некоторые изменения русской «наивной этики».

Ключевые слова: лексическая семантика, языковая картина мира, наивная этика, история слов, семантические оппозиции.

В статье делается попытка проследить историю языковых выражений, соотносимых с понятием «гордость», на протяжении последних двух столетий (в первую очередь глагола гордиться, прилагательного гордый, наречия гордо и существительного гордость), а также установить связь этих изменений с перестройкой русской языковой картины мира. 
На этом приходится остановиться еще и потому, что в последние годы распространился миф о неизменности языковой картины мира всякого конкретного языка. Приведем характерное высказывание из предисловия Анны Павловой к сборнику с несколько претенциозным названием «От лингвистики к мифу: лингвистическая культурология: в поисках “этнической ментальности”». А. Павлова с некоторым (возможно, наигранным) удивлением пишет: «И.Б. Левонтина настаивает на изменчивости языковой картины мира $<\ldots>$ Если картина столь изменчива, то это уже не картина. Это язык» [Павлова 2013: 10]. Понятно, что с тем же успехом можно отрицать возможность каких бы то ни было языковых изменений. Нам говорят, что в германских языках было «передвижение согласных», в результате которого изменилась система консонантизма. «Но это невозможно: если система консонантизма может изменяться, то это уже не система консонантизма - это язык» ${ }^{1}$.

Главное из изменений, которое претерпело понимание выражений, соотносимых с понятием «гордость», состояло в следующем. В русской языковой картине мира, как и в картинах мира многих других языков, сформированных под влиянием традиционной христианской этики, гордость в течение долгого времени понималась как общая жизненная установка, состоящая в чрезмерно и необоснованно высоком мнении о самом себе, часто сочетающемся с презрением по отношению к другим. Это понимание в значительной мере определялось христианской этикой, в которой гордость считалась первым из смертных грехов и противопоставлялась смирению. Соответственно, актуальными были противопоставления гордый vs. смиренный, гордиться vs. смириться. Постепенно, в процессе секуляризации общества, а также в связи с распространением романтических настроений, понятие «гордость» стало переосмысляться. Гордость стала пониматься как чувство человека, который думает, что с ним связано нечто хорошее, из-за чего другие люди будут думать о нем лучше, а в качестве общей жизненной установки гордость стала восприниматься как нечто близкое «чувству собственного достоинства»². При понимании гордости как чувства возникает новое противопоставление гордости и cmыла: если гордость - это чувство человека, который считает, что с ним связано нечто хорошее, из-за чего другие люди будут думать о нем лучше, то cmbl это чувство человека, который считает, что с ним связано нечто плохое, из-за чего другие люди могут думать о нем хуже. Это нашло отражение в новом противопоставлении глаголов гордиться и стылиться ${ }^{3}$.

\footnotetext{
${ }^{1}$ Нелепость пародируемого высказывания А. Павловой тем более удивительна, что автор этого высказывания - лингвист, написавший в свое время ряд вполне разумных лингвистических работ (в частности, работ, касающихся просодической маркированности ряда лексических единиц русского языка).

2 Сходные изменения претерпели слова со значением 'гордость' в целом ряде других европейских языков (ср., например, историю слов proud и pride в английском языке).

${ }^{3}$ В последующем изложении использованы (с определенными уточнениями) некоторые положения, сформулированные в более ранней работе автора [Шмелев 2000]. Примеры использования слов со значением 'гордость' в произведениях Александра Солженицына были приведены в статье [Шмелев 2018].
} 
Как мы знаем, этические представления, характерные для традиционной русской языковой картины мира, оценивали гордость резко отрицательно. Характерны толкования из словаря В.И. Даля:

Гордый 'надменный, высокомерный, кичливый; надутый, высоносый, спесивый, зазнающийся; кто ставит себя самого выше прочих'. <..> Гордым быть, глупым слыть. Гордым Бог противится, а смиренным дает благодать. В убогой гордости дьяволу утеха. Во всякой гордости черту много радости. <..> Гордиться чем 'быть гордым, кичиться, зазнаваться, чваниться, спесивиться' / 'хвалиться чем, тщеславиться; ставить себе что-либо в заслугу, в преимущество, быть самодовольным'. Сатана гордился, с неба свалился; фараон гордился, в море утопился; а мы гордимся, куда годимся? [Даль 1: 388].

Заметим, что как в предлагаемых синонимических заменах и толкованиях, так и в приводимых примерах отрицательная оценка ясно видна не только у прилагательного гордыц̆, но и у глагола гордиться. При этом, как видно и из пояснений, и из приведенного примера, для глагола гордиться характерно абсолютивное употребление (просто гордиться, а не гордиться чем-либо). Характерны ряды синонимов, приводимых Далем для пояснения значения прилагательного гордый и глагола гордиться: надменный, высокомерный, кичливыц̆; надутый, спесивый, зазнаюшийся и кичиться, зазнаваться, чваниться, спесивиться; тщеславиться. В большинстве этих синонимов более или менее ярко представлена отрицательная оценка соответствующего внутреннего состояния и сопутствующего ему поведения.

В сборнике пословиц, собранных Далем, обнаруживается та же отрицательная оценка гордости, например: Гордый покичился, да и в прах свалился [Даль 1957: 729].

Это вполне отвечает общехристианским представлениям. Приведем цитаты из синодального перевода Нового Завета:

... исполнены всякой неправды, блуда, лукавства, корыстолюбия, злобы, исполнены зависти, убийства, распрей, обмана, злонравия, злоречивы, клеветники, богоненавистники, обидчики, самохвалы, горды, изобретательны на зло, непослушны родителям, безрассудны, вероломны, нелюбовны, непримиримы, немилостивы (Рим. 1: 29);

Бог гордым противится, а смиренным дает благодать (Иак. 4: 6; 1 Петр. 5: 5);

Кто учит иному и не следует здравым словам Господа нашего Иисуса Христа и учению о благочестии, тот горд, ничего не знает, но заражен [страстью] к состязаниям и словопрениям (1 Тим. 6: 3);

... люди будут самолюбивы, сребролюбивы, горды, надменны, злоречивы, родителям непокорны, неблагодарны, нечестивы, недружелюбны, непримирительны, клеветники, невоздержны, жестоки, не любящие добра, предатели, наглы, напыщенны, более сластолюбивы, нежели боголюбивы... (2 Тим. 3: 2). 
Характерны также цитаты из «Катихизиса» святителя Филарета (Дроздова), написанного в $1823-1824$ гг.:

... нарушили долг совершенного повиновения Богу и, таким образом, отпали от Него и впали в самолюбие, гордость и злобу;

Гордость и тщеславие относятся к идолопоклонству, потому что гордый выше всего ценит свои способности и преимущества, и, таким образом, они для него суть идол... Такое расположение гордого и тщеславного даже чувственным образом проявилось в вавилонском царе Навуходоносоре, который поставил сам себе золотого идола и велел поклоняться ему.

В литературе того времени такое восприятие гордости, связанной с тем, что субъект необоснованно считает себя лучше других, вполне обычно:

Он много стал о себе думать, важничал перед другими мальчиками и вообразил, что он гораздо лучше и умнее всех их. Нрав Алеши от этого совсем испортился: из доброго, милого и скромного мальчика он сделался гордый и непослушный. Совесть часто его в том упрекала, и внутренний голос ему говорил: «Алеша, не гордись! Не приписывай самому себе того, что не тебе принадлежит; благодари судьбу за то, что она тебе доставила выгоды против других детей, но не думай, что ты лучше их» (А. Погорельский. Черная курица, 1829)4.

Любопытно, что обостренное чувство собственного достоинства также могло восприниматься как проявление отрицательно оцениваемой гордости. Так, в польской культуре чувство собственного достоинства, не позволяющее унижаться и отступать от собственных принципов ради выгоды или избавления от опасностей, ценится чрезвычайно высоко. Для обозначения вытекающей из такой установки готовности к жертвам в польском языке есть специальное слово - honor 5 . В русском восприятии поведение, вытекающее из такой установки, часто представало как высокомерие, надменность, отсутствие подлинного смирения. Соответственно, будучи заимствовано в русский язык в виде гонор, это слово вошло в ряд таких отрицательно окрашенных слов, как спесь, кичливость, самоуверенность, самонадеянность, самомнение и т.д. (проявление гонора, как правило, не одобряется) ${ }^{6}$. При этом гонор часто воспринимался как специфически польское качество, и неслучайно в русской культуре возник стереотип кичливого ляха

4 Этот и некоторые последующие примеры взяты из [НКРЯ].

5 Речь идет лишь об одном из значений слова honor. Здесь нет возможности подробно рассматривать семантические различия польских слов honor и cześć и их соотношение с русским честь (ср анализ в статье [Толстая 2013]). Отметим лишь, что в повести Пушкина «Капитанская дочка» пословица Береги платье с нову, а честь с молоду переведена как «Strzeż ubrania, póki nowe, a honoru od młodu» (переводчики - S. Pollak и T. Stępniewski). В оригинальных польских текстах мне не удалось обнаружить такой пословицы. Замечу, кстати, что выражение слово чести естественно перевести на польский язык именно как stowo honoru.

6 Употребление слова гонор в «положительном» смысле изредка встречалось в ХІХ в., но постепенно сошло на нет. 
(выражение из стихотворения Пушкина «Клеветникам России»), сохранявшийся и в более позднее время ${ }^{7}$.

На этом фоне очень ярким оказывается употребление слова гонор в значении, близком польскому honor, в киносценарии Солженицына «Знают истину танки». Когда восстание заключенных давят при помощи танков, один лишь поляк Гавронский не теряет достоинства:

... Гавронский. Вскинутая голова! Грудь, подставленная под расстрел! Гонор - это честь и долг!

С презрительной улыбкой он оглядывает стреляющий конвой...

Солженицын как бы восстанавливает «исконное» значение, которое слово honor имеет в польском языке [ср.: Шмелев 2013: 490-491].

Но уже в первой половине XIX в. в романтическом дискурсе, а следом и в повседневном употреблении появляются высказывания, в которых гордость, напротив, оценивается скорее положительно и соответствующим образом употребляются и прилагательное гордый, и наречие гордо, и существительное гордость. Ср. примеры из [НКРЯ]:

Как невыразимо величественна военная музыка среди битвы! Как гордо и торжественно звучала она в горах Кавказа! (А. А. Бестужев-Марлинский. Письма из Дагестана, 1831);

Две только драгоценности вынес я из потопа: это гордость души и умиление перед всем, что прекрасно (А. А. Бестужев-Марлинский. Письма, 1830-1837);

... она опустила голову; казалось, ей тяжело продолжать. Но вдруг она подняла ее, гордую и величественную, и, ясно взглянув на меня, сказала: - Я сдержала слово! < ..> Я готов был броситься к ногам этой женщины. Как высока, как сильна, как чудно изящна казалась она мне в эту минуту признания! (А. И. Герцен. Сорока-воровка, 1846).

Словоупотребление Марлинского можно связать с романтическим настроем его произведений. Но для Герцена такое использование слова гордыц̆, возможно, уже воспринималось как вполне общепринятое.

«Положительная» окраска гордости обычно была обусловлена одним из следующих двух моментов. С одной стороны, гордость бывает связана с чувством, которое возникает у человека, когда он сам или близкие ему люди, как ему кажется, сделали что-то очень хорошее (из-за чего другие люди могут думать о нем лучше). Это естественное человеческое чувство, в котором трудно видеть чтото плохое. С другой стороны, гордость бывает связана с тем, что человек сознает свою ценность в качестве самостоятельной личности и потому не хочет зависеть от других людей и готов отстаивать свою независимость. Это сходно

7 О слове honor и стоящей за ним установке и о семантическом сдвиге при заимствовании его в русский язык в виде гонор см. [Wierzbicka 1992: 218-221; Шмелев 2012: 312-314]. 
с установкой, лежащей в основе польского концепта honor. Ср. следующий пример из [НКРЯ]:

Раненный два раза, он отвечал гордо на предложение к сдаче, что честь русского солдата повелевает умереть с оружием в руках (Ф.В. Булгарин. Воспоминания, 1846-1849) ${ }^{8}$.

Положительные коннотации гордости встречаются и в поэзии того времени. Так, если в 1831 г. Пушкин еще эксплуатирует стереотип кичливого ляха, то в 1836 г. в стихотворении «Памятник» он уже использует по отношению к полякам перифрастическое обозначение гордый внук славян без каких-либо отрицательных коннотаций.

Еще более заметным оказался сдвиг, связанный с глаголом гордиться. Значение 'быть чрезмерно высокого мнения о себе самом, необоснованно считать себя лучше других' (т. е. гордиться вообще, безотносительно к чему-либо) постепенно вытесняется другим - человек гордится чем-то, т. е. 'считает, что с ним связано нечто хорошее, из-за чего другие люди могут думать о нем лучше'9. Такая гордость может быть естественна и не подлежать этическому осуждению. Ср.:

Он гордился тем, что был братом его, и такая гордость не только простительна, но и естественна и благовидна (П.А. Вяземский. Старая записная книжка, 1830-1870).

Возникает новое противопоставление: гордиться <чем-то $>$ vs. cmblдиться <чего-то>:

Франции всегда подражает Северная Европа, и теперь у нас дворянство не только не стыдится торговли, напротив, люди гордятся оборотами, спекуляциями, подрядами и откупами, как предки наши гордились воинскими или гражданскими подвигами (Ф. В. Булгарин. Воспоминания, 1846-1849);

Первый приехал стряпчий с женою, хорошенькою дочерью городничего, которая была уже в счастливом положении, чего очень стылилась, а муж, напротив, казалось, гордился этим (А.Ф. Писемский. Тысяча душ, 1858).

В этих примерах обращает на себя внимание слово напротив, прямо указывающее на то, что гордость и стылд противопоставляются. В дальнейшем противопоставление гордиться vs. стыдиться становится совершенно обычным и встречается во множестве текстов.

Глагол гордиться начинает все более активно употребляться в первом лице (горжусь, гордимся), а также в императиве без отрицания и в сочетании с модальным

${ }^{8}$ Можно было бы говорить, что в таком словоупотреблении сказалось польское происхождение Фаддея Булгарина.

9 Разумеется, такие употребления встречались и раньше: можно было гордиться <чем-то>, как можно кичиться <чем-то>. Речь идет о том, что абсолютивные употребления ушли на периферию. 
глаголом во втором лице (гордись, mы можешь гордиться). Они встречались и прежде, но существенно реже.

В качестве реакции на такие употребления актуализуются призывы к смирению, к тому, чтобы не гордиться. Приведем два отрывка из стихотворений Алексея Хомякова:

«Гордись! - тебе льстецы сказали. Земля с увенчанным челом, Земля несокрушимой стали, Полмира взявшая мечом!»
Не в пьянстве похвальбы безумной, Не в пьянстве гордости слепой, Не в буйстве смеха, песни шумной, Не с звоном чаши круговой;

России, 1839 Но в силе трезвенной смиренья И обновленной чистоты...

Раскаявшейся России, 1854

Первый отрывок показывает, что вполне обычным стал призыв гордись, причем обращенный к целой стране, однако этот призыв используют «льстецы», т. е. обманщики. И Хомяков продолжает: «Не верь, не слушай, не гордись!» Иными словами, не следует поддаваться соблазну впасть в смертный грех гордости, а необходимо обрести дух смирения: «И вот за то, что ты смиренна, / <..> станешь в славе ты чудесной / Превыше всех земных сынов».

Второй отрывок эксплицитно противопоставляет слепую гордость, которой человек упивается, и трезвенную силу смиренья, вновь актуализуя традиционное противопоставление гордости и смирения.

Это противопоставление заново актуализуется и в знаменитой «Пушкинской речи» Достоевского (1880), в его призыве:

Смирись, гордый человек, и прежде всего сломи свою гордость.

«Новое» представление о гордости, в соответствии с которым она воспринимается как положительное качество, смыкающееся с «чувством собственного достоинства», постепенно становилось преобладающим, хотя продолжались попытки отстоять «старое» понимание. Когда одна писательница в соответствии с «новым» пониманием назвала Чехова гордылм мастером, он возразил: «Почему вы назвали меня гордым мастером? Горды только индюки» [Чуковский 1958: 459]. Показательны также воспоминания Наталии Соколовой, дочери известного духовного писателя Николая Евграфовича Пестова. Юную Наташу Пестову (будущую матушку Соколову) родители оберегали от влияния советской идеологии, давая ей читать лишь дореволюционную и переводную литературу. Однако оказалось, что и в дореволюционной литературе содержались чуждые христианству ценности. Вот что об этом пишет сама матушка Соколова в своих воспоминаниях, озаглавленных «Под кровом Всевышнего»:

Находясь в школе в безрелигиозном обществе, начитавшись светской литературы, я нравственно падала. Понятие «гордость» тогда превозносилось, особенно это сквозило в произведениях Лидии Чарской, которыми я увлекалась. Еще не сознавая в этом греха, я душой превозносилась над другими детьми. 
Дело не просто в том, что Лидия Чарская употребляла слово гордость в «новом» значении, но скорее в том, что гордость считалась непременной принадлежностью всякого человека, обладающего чувством собственного достоинства.

В советское время положительное понимание гордости полностью возобладало. Оно поддерживалось использованием слов со значением 'гордость' в «неоромантической» словесности начала XX в., например у Максима Горького, цитаты из которого знал каждый советский школьник (гордо реет Буревестник; гордый Буревестник реет смело и свободно; Человек! Это звучит гордо! и т. п.). Связь гордости и готовности отстаивать свою независимость ярко отражалось в революционной литературе, например в словах из песни «Варшавянка» на слова Г. Кржижановского: Но мы подымем гордо и смело / Знамя борьбы за рабочее дело... Однако сходное словоупотребление стало обычным и для текстов, не имеющих отношения к революционной борьбе (Врагу не сдается наш гордый «Варяг»» $\left.{ }^{10}\right)$.

Характерно, что когда Корней Чуковский упомянул приведенный выше диалог «гордый мастер - горды только индюки» в своей статье о Чехове, то, поскольку в понимании Чуковского слово гордый было окрашено уже почти исключительно положительно, далее он (возможно, не замечая иронии) вполне сочувственно цитировал высказывание театрального критика Кугеля: «Чехов был человек гордый», - и дополнил его следующим комментарием: «Такой же гордости требовал Чехов от всех» [Чуковский 1958: 483]. И Чуковский продолжал: «К смирению и кротости он был совершенно не склонен. <... Ибо чувство собственного достоинства $<\ldots>$ всегда было регулятором его поведения» [Там же: 484]. Мы видим, что Чуковский следует традиционному противопоставлению гордость vs. смирение, но переосмысляет его в соответствии с новым словоупотреблением.

В этом отношении особенно показательна знаменитая цитата из выступления Алексея Суркова на съезде советских писателей в 1934 г.:

Слово это - гуманизм. Рожденное в замечательную эпоху, это слово было запакощено и заслюнявлено тщедушными вырожденцами. Они подменили могучее его звучание - человечность - христианским сюсюканьем - человеколюбием... У нас по праву входят в широкий поэтический обиход понятия Любовь, Радость, Гордость, составляющие содержание Гуманизма. Но некоторые... поэты как-то стороной обходят четвертую сторону гуманизма, выраженную в суровом и прекрасном понятии НЕНАВИСТЬ.

Почти все, кто комментировал эту поразительную цитату, обращали внимание именно на апологию ненависти, тем более что это слово и было выделено в стенограмме. Но для понимания особенностей языковой концептуализации мира важно не столько то, что эксплицитно декларируется, сколько то, что как бы остается

10 Эта строчка представляет собою перевод с немецкого (Der stolze Warjag ergibt sich nicht из песни «Der Warjag» на слова австрийского поэта Рудольфа Грейнца). Однако показательно, что и в песне о гибели «Варяга» с оригинальным русским текстом (Плещут холодные волныс...) также используется эпитет гордый, а именно: Бьется с неравною силой / Гордый красавеи «Варяг». 
за скобками, воспринимается как само собою разумеющееся; именно это язык подсказывает своим носителям. То, что гордость (слово, напечатанное в стенограмме с прописной буквы) стала восприниматься как очевидно положительное качество (которое только потому и могло стать одной из составляющих «гуманизма»), стоящее в одном ряду с любовью и радостью, уже никого не удивило: это соответствовало словоупотреблению большинства носителей русского языка того времени.

Любопытно, кстати, что слово гордыня, сохранившее отрицательную окраску в неидеологическом дискурсе, стало использоваться с отрицательной окраской и в языке советской идеологии (в значении 'противопоставление себя коллективу'). Отсюда цитата:

Писательница Вера Панова такими словами определила свое отношение к Пастернаку: «В этой озлобленной душе, которая раскрывалась во всем этом деле начиная с написания романа и кончая письмом, - нет ни чувства родной почвы, ни чувства товарищества, кроме безмерного эгоизма, неприемлемого в нашей стране, кроме невыносимой гордыни, неприемлемой в коллективистском обществе. Видеть это отторжение от Родины и озлобление даже жутко» (Записка Отдела культуры ЦК КПСС об итогах обсуждения на собраниях писателей вопроса «О действиях члена Союза писателей СССР Б. Л. Пастернака, несовместимых со званием советского писателя») $)^{11}$.

Советские штампы (прекрасные, гордые люди) выражали именно «новое» представление о гордости. Собственно, сам штамп возник еще в XIX в.:

... раздражить, обидеть, оскорбить ее, чистую, прекрасную, гордую... (Ф. М. Достоевский);

... прекраснылй, гордыцй польский лоб... (Н. С. Лесков);

... прекрасная, гордая Вера... (И.А. Гончаров).

Он неоднократно использовался и в литературе начала XX в., например:

И увидел Елеазар прекрасное гордое лицо, осиянное славой... (Л. Андреев);

Стоит, опустив ресницы, прекрасная и гордая... (Л. Андреев).

Да и у Чарской этот штамп встречается неоднократно:

Я увидела прекрасное, гордое лицо, еще далеко не старое, но бледное как мрамор и высокий лоб под короной белых как лунь, седых кудрей (Л.А. Чарская. Записки институтки, 1901);

Я вижу перед собой угрюмое бледное лицо, пламенные глаза, прекрасную, гордую голову, и в груди моей разливается огонь сочувствия, жалости безысходной тоски (Л.А. Чарская. Мой принц, 1915).

11 Разумеется, за адекватность передачи слов Веры Пановой может нести ответственность только Отдел культуры ЦК КПСС. 
Но в советское время он стал настолько избит, что превратился в объект насмешек, как в песне Галича «Леночка»:

Прекрасная и гордая,

Заметна за версту...

«Старое» понимание гордости в ее противопоставлении подлинному смирению в то время почти ушло в прошлое. Лишь только в нонконформистском и в эмигрантском словоупотреблении понятию «гордость» могло придаваться «старое» значение, как в статье «Демонская твердыня» свящ. Александра Ельчанинова:

... главные этапы развития гордости от легкого самодовольства до крайнего душевного омрачения и полной гибели;

Гордость есть крайняя самоуверенность, с отвержением всего, что не мое, источник гнева, жестокости и злобы, отказ от Божией помощи.

Однако и в нонконформистском словоупотреблении последнего полувека понятию «гордость», как правило, придавалось положительное значение. В частности, почти всегда с положительными коннотациями использовал его Солженицын. При этом интересно, что Солженицын несколько раз демонстрировал понимание гордости как важнейшей ценности польской культуры, соединенной с готовностью к жертвам. Это особенно ярко отражено в известном эпизоде из «Архипелага ГУЛАГ»:

И тут я понял, что значит польская гордость - и в чем же были их самозабвенные восстания. Тот самый инженер поляк Юрий Венгерский был теперь в нашей бригаде. Он досиживал свой последний десятый год. Даже когда он был прорабом - никто не слышал от него повышенного тона. Всегда он был тих, вежлив, мягок.

А сейчас - исказилось его лицо. С гневом, с презрением, с мукой он откинул голову от этого шествия за милостыней, выпрямился и злым звонким голосом крикнул:

— Бригадир! Не будите меня на ужин! Я не пойду!

Взобрался на верх вагонки, отвернулся к стене и - не встал. Мы ночью пошли есть, а он - не встал! Он не получал посылок, он был одинок, всегда не сыт и не встал. Видение дымящейся каши не могло заслонить для него - бестелесной Свободы!

И напрашивающийся вывод, выраженный в риторическом вопросе:

Если бы все мы были так горды и тверды - какой бы тиран удержался?

Впрочем, секуляризованное понимание гордости, нашедшее отражение в «новом» словоупотреблении, никак не может считаться исключительной принадлежностью русского языка советского времени. Английский язык (особенно в американском варианте) пошел в этом отношении еще дальше, так что смысл слов proud и pride отчасти даже стерся. Вера Белоусова [2011] обратила внимание на то, что фраза I am so proud of you!, произнесенная родителем в ответ на сообщение 
ребенка, что он получил хорошую оценку за контрольную работу, функционально близко русским похвалам Молодец! или Умница!. Различие разговорных рутин объясняется тем, что русские культурные скрипты предполагают возможность оценки человека, а американские предписывают говорить о себе и своих чувствах, а не наклеивать ярлыки.

И заметим, что, когда слово гордость метонимически указывает на причину чувства, т. е. на то, чем можно гордиться, как во фразе Петя - гордость нашей школьл, для этической оценки вообще не остается места: ясно, что говорящий не обвиняет в смертном грехе гордости ни Петю, ни школу. Глагол гордиться стал почти исключительно употребляться для обозначения чувства, которое может оцениваться положительно, если говорящий считает причину гордости достаточным основанием для возникновения этого чувства (например, в сочетаниях по праву гордиться, с полным основанием гордиться, во фразе $B$ й можете гордиться..., в форме гордись и т. п.). Это употребление проникло и церковно-проповеднический язык, и, когда Святейший Патриарх Алексий II, обращаясь к родственникам погибших подводников, говорил: «Вы можете ими гордиться», - он, конечно, не призывал слушателей впадать в смертный грех гордости.

Тем самым противопоставление гордиться vs. стыдиться, пришедшее на смену противопоставлению гордиться vs. смириться, стало практически общепринятым. Приведем пример из романа Солженицына «В круге первом», когда инженер-энергетик, свесившись с верхней койки и обращаясь к Рубину, естественным образом использует это противопоставление:

Надо так перестроить совесть человечества, чтобы люди гордились только трудом собственных рук и стылдились быть надсмотрщиками, «руководителями», партийными главарями.

И это дало почву для противопоставления гордости и стыла. В самом деле, в современном русском языке толкования слов гордость (в одном из значений) и стыд почти симметричны: гордость - это 'приятное чувство, вызванное тем, что, по мнению субъекта, он или кто-то, к кому он имеет непосредственное отношение, обладает чем-то очень хорошим или сделал что-то очень хорошее, из-за чего другие люди могут думать о нем лучше', тогда как cmbld - это 'неприятное чувство, которое испытывает человек, вопреки своей воле попавший или могущий попасть в ситуацию, по его мнению, в каком-то отношении отклоняющуюся от нормы, из-за чего другие люди думают или могут думать о нем хуже'12.

Встает вопрос о том, как отразить современное употребление слов со значением 'гордость' в семантическом описании и, в частности, в толковых словарях. Соответствует ли «положительное» и «отрицательное» отношение к гордости разным лексическим значениям слова? Аналогичная проблема встает в связи со словами со значением 'гордость' в других языках. Напомним, что А. Вежбицка (в разделе «Moral Concepts» книги [Wierzbicka 1992]) рассматривает английское слово pride

12 Разумеется, это лишь приблизительные толкования, не претендующие на точность. 
как оценочно нейтральное и именно этим объясняет его способность использоваться как в положительных, так и в отрицательных контекстах, тогда как словари усматривают у этого слова два значения: «положительное» (чувство собственного достоинства) и «отрицательное» (преувеличенно высокое мнение о себе самом). Именно так трактуется слово pride в словарях [Hornby et al. 1958; Macmillan; Webster]. Ср. соответствующие словарные статьи:

pride 1) 'too high an opinion of one's own worth, rank, qualities, etc.; conceit; arrogance; haughtiness'. Pride goes before a fall; 2) 'a knowledge of one's own true worth and character, preventing one from doing anything base or mean'; also proper pride. His pride would not allow him to accept any reward [Hornby et al. 1958];

pride 1) 'sense of one's personal worth or dignity; self-respect': Despite years of poverty, the man had maintained his pride; 2) 'exaggerated or unreasonable sense of one's worth or importance': Ken knew he was wrong, but his foolish pride kept him from apologizing [Macmillan];

pride 1a) 'an unduly high opinion of oneself; exaggerated self-esteem; conceit'; 1b) 'haughty behavior resulting from this; arrogance'; 2 'proper respect for oneself; sense of one's own dignity or worth; self-respect' [Webster].

Сходным образом словари английского языка подают и соответствующие значения прилагательного proud:

proud 1) (in a good sense) 'having or showing a proper pride or dignity'. He was too proud to complain; 2) (in a bad sense) 'esteeming oneself too highly; thinking oneself superior; haughty; arrogant'. He was too proud to join our party [Hornby et al. 1958];

proud 2) 'having a sense of one's personal worth or dignity': He is too proud to beg; 3) 'having an exaggerated or unreasonable sense of one's personal worth or dignity; haughty': Harold is a proud, vain man [Macmillan].

Как видно из толкований, отрицательная окраска возникает у слова proud, как правило, в тех случаях, когда связанная с ним самооценка субъекта воспринимается говорящим как необоснованно завышенная. Однако не вполне ясно, что лучше: трактовать это как распределение по контекстам разных лексических значений или как контекстную модификацию единого лексического значения.

Аналогичный вопрос встает и в отношении русских слов гордиться, гордыци, гордо и гордость. Выясняется, что даже лингвисты, принадлежащие Московской семантической школе, не едины в трактовке этих единиц. В «Новом объяснительном словаре синонимов», в статье «Гордиться» Ю. Д. Апресян дает ряду гордиться, кичиться толкование 'испытывать чувство, какое бывает, когда субъект считает, что он или близкий ему человек имеет или сделал нечто очень хорошее и что из-за этого другие люди будут лучше о нем думать' [Апресян 2004]. Он указывает, что оба глагола управляют формой творительного падежа со значением предмета и одновременно причины гордости, и добавляет, что глагол кичиться в этом 
же лексическом значении может употребляться абсолютивно, а глагол гордиться в абсолютивном употреблении имеет другое значение — 'вести себя высокомерно, задаваться’ [Там же: 232]. А в «Активном словаре русского языка» В. Ю. Апресян выделяет у глагола гордиться единственное значение, не предусматривая других значений и, соответственно, возможности абсолютивного употребления [Апресян 2014]. Можно полагать, что В. Ю. Апресян считает абсолютивное употребление глагола гордиться устаревшим. Тем не менее примеры, в которых гордиться явно означает 'вести себя высокомерно, задаваться' 13 , встречаются в современных текстах, хотя и действительно не очень часто:

Ты, Ларионов, не гордись! Ты, брат, ничем нас не лучше! (М. Шишкин. Всех ожидает одна ночь, 1993-2003).

Для слов гордый и гордость ситуация несколько более сложная. Наряду со значениями, непосредственно соотносимыми с глаголом гордиться (в основном значении) и описывающими чувство человека, который считает, что с ним связано нечто хорошее (а также метонимически производные значения или типы употребления), слова гордый и гордость могут употребляться не по отношению к чувству, а по отношению к общей установке человека, его мнению о себе и вытекающему из этого поведению. Если гордость как чувство в общем не подлежит этической оценке, то гордость как общая установка может оцениваться положительно, нейтрально или отрицательно. В случае положительной или нейтральной оценки гордость сближается с чувством собственного достоинства и нежеланием зависеть от других людей; в случае отрицательной оценки гордость сближается с высокомерием и самомнением. В соответствующих статьях «Активного словаря русского языка» [Гловинская 2014; Санников 2014] значения общей установки (и метонимически связанные с ними значения и типы употребления) отделены от значений, указывающих на чувство, и при этом для значений общей установки положительной и отрицательной оценке гордости соответствуют разные значения (т. е. принимается решение, сходное с решениями английских и американских лексикографов, а не с решением Анны Вежбицкой).

Интерес представляет стилистическая характеристика отрицательно оцениваемой гордости. Если А. В. Санников [2014] значение слова гордость, указывающее на то, что носитель данной установки слишком высоко ценит себя и, возможно, считает себя выше других людей, характеризует как книжное или церковное ${ }^{14}$, то М.Я. Гловинская [2014] соответствующее значение слова гордый (т. е. такой, какой, по мнению говорящего, имеет слишком высокое мнение о себе: Ишь, какой гордыцй) описывает как разговорное. В целом, хотя это и может казаться парадоксальным, и та и другая характеристики применимы к большинству случаев употребления этих слов. Но все же стоит заметить, что слово гордость в рассматриваемом

13 Обратим внимание на то, что именно это значение является мотивирующим для производного глагола возгордиться.

14 Это соответствует выводу, сделанному в более ранней работе [Санников 2006: 451]. 
значении может употребляться не в книжных или церковных, а вполне в разговорных и даже сниженных контекстах, например: ... у него пока гордость играет [https://otvet.mail.ru/question/66121160]; Интересно, тебе реально пофиг или тоже гордость играет? [https://twitter.com/dolche_milk/status/537307498144104448]. Можно привести и менее сниженные примеры. Вспомним русскую поговорку Нарастает гордость на сердие, как сало на свинье (эта поговорка многим памятна, потому что цитируется в четвертой главе «Архипелага ГУЛАГ»). Едва ли поговорки как таковые можно отнести к книжным или тем более церковным выражениям. Но очевидно, что слово гордость употреблено в ней именно в значении слишком высокой самооценки в сочетании с презрением к другим людям.

Пожалуй, несколько жаль, что в словник «Активного словаря русского языка» не вошло наречие гордо. Как кажется, интересная особенность этого слова заключается в том, что оно весьма часто характеризует внешнее поведение, одновременно намекая на то, какое чувство или какая установка могут лежать за этим поведением.

В целом представляется, что приведенный материал свидетельствует о необходимости детального анализа всех идиосинкратических особенностей каждой отдельной лексической единицы. Собственно, это и есть то, что Ю.Д. Апресян уже довольно давно называл лексикографическим портретированием, используя выражение А.К. Жолковского, но существенно расширяя его. При этом, как справедливо отмечено в [Апресян 2006: 29-30], обнаруживается «принципиальное единство проблем в синхронии, диахронии и лексической типологии», демонстрирующее «тесную связь синхронии и диахронии в семантике». В этом отношении полное описание лексической единицы должно было бы включать ее историю и сопоставление с аналогичными единицами других языков. В применении к русским словам со значением 'гордость' мы можем констатировать, что старое противопоставление гордости и смирения сменилось новым - противопоставлением гордости и стылда. При этом «старое» противопоставление еще актуально для некоторых типов контекстов, например религиозных, а «новое» еще не успело пронизать всю систему языка. «Старое» противопоставление охватывало слова разных частей речи: противопоставлялись прилагательные гордый и смиренный, существительные гордость и смирение, наречия гордо и смиренно (гордо вскинул голову vs. смиренно опустил голову). Лишь для глаголов гордиться и смириться четкость противопоставления нарушается, поскольку гордиться - это глагол несовершенного вида, обозначающий внутреннее состояние субъекта, а смириться - глагол совершенного вида, указывающий на возникновение внутреннего состояния (в этом отношении глаголу смириться противопоставлен не столько глагол гордиться, сколько глагол возгордиться). В «новом» противопоставлении участвуют лишь некоторые слова со значениями 'гордость' и 'стыд'. Оно четко выражено для глаголов гордиться и стылдться, менее четко - для слов гордость и стьлд. Это связано с тем, что для слова гордость значение испытываемого чувства не единственное и, вероятно, даже не основное (на первый план выходит общая установка на независимость и чувство собственного достоинства, а также сохраняется значение 
самомнения), а слово стыд может еще обозначать самое способность испытывать чувство стыда (совсем забыла стыл), а также давать общую характеристику ситуации (Какой стыл!). Наречие гордо вообще не соотносится со словом стылно, поскольку стыдно в современном языке - предикатив, а не обстоятельство образа действия [Булыгина, Шмелев 2000: 217-219]. Наконец, гордый тоже вообще не соотносится со словом стылнылй, поскольку стылный характеризует не человека, а обсуждаемую ситуацию, и к тому же в современном языке является уходящим и используется преимущественно в полемических контекстах [Там же: 220-221].

Можно добавить, что в следующем примере из «Ответа молодому ученому» Солженицына гордость противопоставляется не стылу, а стылдивости:

Так говоря «интересно» - говорите, по крайней мере, это не с гордостью, а со стылдливостью! - со стьлдивостью за ту утреннюю яичницу, и за то, что вам не приходится возить батонов в мешке сперва в тесном поезде, потом в переполненном автобусе. С певчей птицей себя не сравнивайте, ибо она сама себе добывает пищу и поет только в промежутке между невеселыми этими хлопотами. Ответ «мне просто интересно» — безнравственный.

Обычно слово стыдливость относится к более или менее постоянному свойству человека - склонности испытывать чувство смущения. Однако в данном примере слово стылдивость обозначает актуальное чувство, близкое чувству стыда. Очевидно, слово cmыl казалось Солженицыну слишком сильным и он «смягчил» его. Тем не менее видно, что описываемое чувство близко именно стыду, а не смирению, так что и здесь мы имеем дело с «новым» противопоставлением.

Сопоставление с другими языками иногда может пролить свет на структуру полисемии рассматриваемых слов. Так, известно, что при обозначении актуальных эмоциональных состояний русский язык часто использует глагол там, где, скажем, по-английски используется прилагательное ( $X$ is angry и $X$ сердumcя). Соответственно, естественно переводить английское I am proud of you как Я горжусь тобою (а не Я горд тобою или Я горд за тебя). Правда, как уже отмечалось выше, в силу различия культурных скриптов перевод $Я$ горжусь тобою тоже звучит не очень естественно во многих контекстах. Но в любом случае нейтральное обозначение актуальной эмоции осуществляется при помощи глагола гордиться, и это приводит к тому, что для прилагательного гордый значение актуальной эмоции уходит на второй план, тем самым структура полисемии и контексты употребления каждого из значений прилагательного гордый не вполне соответствуют структуре полисемии английского proud. Разумеется, все приведенные наблюдения должны быть дополнены сопоставлением с другими языками и тщательным анализом переводных соответствий, в том числе в реальных переводах (например, на материале параллельных корпусов). Но это дело будущего.

Рассмотренные семантические сдвиги отражают некоторые изменения русской «наивной этики». Представление, согласно которому плохо, если человек преувеличивает свои достоинства, считает себя лучше других людей и вследствие этого относится к ним с пренебрежением, смотрит на них свысока и ведет себя 
соответствующим образом, не исчезло из русской «наивной этики», но в какой-то степени ушло на задний план. Оно представлено в целом ряде языковых выражений, отражающих отрицательную оценку таких свойств и вытекающего из них поведения (существительных высокомерие, гонор, гордыня, спесь, прилагательных высокомерный, надменныцй, спесивый, кичливый, глаголах задаваться, кичиться и др.). Однако большинство таких выражений не относится к числу самых употребительных, их можно характеризовать как книжные или, напротив, разговорные. Это же верно в отношении уходящих или сдвинувшихся на периферию значений слов гордиться, гордый, гордость. На первый план вышло представление, согласно которому хорошо, когда человек обладает чувством собственного достоинства и не хочет зависеть от других людей, а также когда человек знает, что с ним связано нечто хорошее и радуется этому. Именно это представление отражается в самых характерных для современной речи употреблениях слов гордиться, гордо, гордый и гордость.

\section{Литература}

Апресян В.Ю. Гордиться // Апресян В. Ю., Апресян Ю. Д., Бабаева Е. Э., Богуславская О. Ю., Галактионова И. В., Гловинская М. Я., Иомдин Б. Л., Крылова Т.В., Левонтина И. Б., Лопухина А. А., Птенцова А. В., Санников А. В., Урысон Е. В. Активный словарь русского языка. Т. 2 / отв. ред. Ю. Д. Апресян. М. : Языки славянской культуры, 2014. С. 651.

Апресян Ю.Д. Гордиться, кичиться // Апресян В.Ю., Апресян Ю.Д., Бабаева Е.Э., Богуславская О.Ю., Галактионова И.В., Гловинская М.Я., Григорьева С.А., Иомдин Б.Л., Крылова Т.В., Левонтина И.Б., Птенизова А.В., Санников A. B., Урысон E. B. Новый объяснительный словарь синонимов русского языка / под общ. рук. Ю. Д. Апресяна. М. : Языки славянской культуры, 2004. С. 230-234.

Апресян Ю. Д. Предисловие // Апресян В. Ю., Апресян Ю. Д., Бабаева Е. Э., Богуславская О. Ю., Иомдин Б. Л., Крылова Т. В., Левонтина И. Б., Санников А. В., Урысон Е. В. Языковая картина мира и системная лексикография / под ред. Ю. Д. Апресяна. М. : Языки славянской культуры, 2006. С. 23-30.

Белоусова B. Lost in translation: романтики и прагматики // Новый мир. 2011. № 2. C. 146-157.

Бульгина Т.В., Шмелев А.Д. Грамматика позора // Логический анализ языка. Языки этики / отв. ред. Н. Д. Арутюнова, Т. Е. Янко, Н.К. Рябцева. М. : Языки русской культуры, 2000. С. 216-234.

Гловинская М.Я. Гордый // Апресян В.Ю., Апресян Ю.Д., Бабаева Е. Э., Богуславская О. Ю., Галактионова И. В., Гловинская М. Я., Иомдин Б. Л., Крылова Т. В., Левонтина И. Б., Лопухина А. А., Птенцова А. В., Санников А. В., Урысон Е. В. Активный словарь русского языка. Т. 2 / отв. ред. Ю. Д. Апресян. М. : Языки славянской культуры, 2014. С. 652-653.

Даль В.И. Толковый словарь живого великорусского языка : в 4 т. М. : Художественная литература, 1935. 
Даль В. И. Пословицы русского народа. М. : Гос. изд-во худ. лит., 1957. 204 с.

HКРЯ - Национальный корпус русского языка [Электронный ресурс]. URL: http://ruscorpora.ru

Павлова A. B. Предисловие составителя // От лингвистики к мифу: Лингвистическая культурология в поисках «этнической ментальности» / ред. И. Ф. Данилова. СПб. : Антология, 2013. С. 5-24.

Санников А. В. Понятия достоинства и смирения // Апресян В. Ю., Апресян Ю. Д., Бабаева Е. Э., Богуславская О. Ю., Иомдин Б. Л., Крылова Т. В., Левонтина И. Б., Санников А.В., Урысон Е. В. Языковая картина мира и системная лексикография / под ред. Ю. Д. Апресяна. М. : Языки славянской культуры, 2006. С. 405-468.

Санников А.В. Гордость // Апресян В.Ю., Апресян Ю.Д., Бабаева Е. Э., Богуславская О. Ю., Галактионова И. В., Гловинская М. Я., Иомдин Б. Л., Крылова Т. В., Левонтина И.Б., Лопухина А. А., Птенщова А. В., Санников А. В., Урысон Е. В. Активный словарь русского языка. Т. 2 / отв. ред. Ю. Д. Апресян. М. : Языки славянской культуры, 2014. С. 651-652.

Толстая С. М. Русская честь и польский honor // Etnolingwistyka. Problemy języka i kultury. 2013. T. 25. S. 9-21.

Чуковский К. Люди и книги. М. : Гос. изд-во худ. лит., 1958. 544 с.

Шмелев А. Д. Плюрализм этических систем в свете языковых данных // Логический анализ языка: Языки этики / отв. ред. Н.Д. Арутюнова, Т.Е. Янко, Н.К. Рябцева. М. : Языки русской культуры, 2000. С. 380-389.

Шмелев А. Д. Русский взгляд на «западные» концепты: языковые данные // Эволюция понятий в свете истории русской культуры / отв. ред. В. М. Живов, Ю. В. Кагарлицкий. М. : Языки славянских культур, 2012. С. 306-324.

Шмелев А.Д. Лингвистические мотивы в творчестве Солженицына: на пути к «Красному Колесу» // Жизнь и творчество Александра Солженицына: на пути к «Красному Колесу» / сост. Л. И. Сараскина. М. : Русский путь, 2013. С. 491-496.

Шмелев А.Д. Гордость, стыд и позор в произведениях Александра Солженицына // Солженицынские тетради. 2018. Вып. 6. С. 80-110.

Hornby A. S., Gatenby E.V., Wakefield H. Advanced learner's dictionary of current English. London : Oxford University Press, 1958. 1528 p.

Macmillan — Macmillan Dictionary. New York : Macmillan Publishing Co., 1973. $1158 \mathrm{p}$.

Webster - Webster's New World dictionary of American English / ed. by V.E. Neufeldt. $3^{\text {rd }}$ ed. Cleveland ; New York : Simon \& Schuster, 1988. 1574 p.

Wierzbicka A. Semantics, Culture, and Cognition. Universal Human Concepts in Culture-Specific Configurations. New York : Oxford University Press, 1992. 487 p. 


\author{
A.D. Shmelev \\ Vinogradov Russian Language Institute of the Russian Academy of Sciences \\ Moscow Pedagogical State University \\ St Tikhon's Orthodox University \\ (Moscow, Russia) \\ shmelev.alexei@gmail.com
}

\title{
GORDOST' 'PRIDE' IN THE HISTORY OF THE RUSSIAN LANGUAGE AND RUSSIAN CULTURE: FROM THE STRONGHOLD OF DEMONS TO SELF-RESPECT
}

This paper studies the evolving meaning of some Russian linguistic expressions referring to the notion of 'pride' as well as the relation of these expressions to certain shifts in the Russian linguistic worldview. For a long time, the Russian linguistic model of the world conceptualized 'pride' as arrogance, that is, an unduly high opinion of oneself and haughty behavior resulting from this. That conceptualization had been shaped by the traditional Christian ethos, which treated 'pride' as the first of the grievous sins, the lack of humility befitting a creature of God. As a result of secularization and the rethinking of the traditional view, 'pride' came to refer to feeling something good because you or people connected with you have done or got something good. With reference to the general attitude of a person, it came to be interpreted as self-respect, that is, a knowledge of one's own true worth and character, preventing one from doing anything base or mean.

Key words: lexical semantics, linguistic conceptualization of the world, ethics, conceptual history, semantic oppositions.

\section{References}

Apresyan V.Yu. [Gordit'sya 'to be proud']. Apresyan V.Yu., Apresyan Yu.D., Babaeva E. E., Boguslavskaya O.Yu., Galaktionova I. V., Glovinskaya M.Ya., Iomdin B.L., Krylova T. V., Levontina I. B., Lopukhina A. A., Ptentsova A. V., Sannikov A. V., Uryson E. V. Aktivnyi slovar' russkogo yazyka T. 2 [The Active dictionary of the Russian language. Vol. 2]. Yu.D. Apresyan (Ed.). Moscow, Yazyki slavyanskoi kul'tury Publ., 2014, p. 651. (In Russ.)

Apresyan Yu.D. [Gordit'sya 'to be proud', kichit'sya 'to be on one's high horse']. Apresyan V.Yu., Apresyan Yu.D., Babaeva E.E., Boguslavskaya O.Yu., Galaktionova I. V., Glovinskaya M.Ya., Grigor'eva S. A., Iomdin B. L., Krylova T. V., Levontina I. B., Ptentsova A.V., Sannikov A.V., Uryson E. V. Novyi ob”yasnitel'nyi slovar' sinonimov russkogo yazyka [The New Explanatory dictionary of Russian synonyms]. Yu.D. Apresyan (Ed.). Moscow, Yazyki slavyanskoi kul'tury Publ., 2004, pp. 230-234. (In Russ.)

Apresyan Yu.D. [Preface]. Apresyan V.Yu., Apresyan Yu.D., Babaeva E.E., Bo-

guslavskaya O.Yu., Iomdin B. L., Krylova T. V., Levontina I.B., Sannikov A. V., Uryson E. V. Yazykovaya kartina mira i sistemnaya leksikografiya [The Linguistic worldview 
and systemic lexicography]. Yu.D. Apresyan (Ed.). Moscow, Yazyki slavyanskoi kul'tury Publ., 2006, pp. 23-30. (In Russ.)

Belousova V. [Lost in translation: romantics and pragmatists]. Novyi mir, 2011, no. 2, pp. 146-157. (In Russ.)

Bulygina T.V., Shmelev A.D. [The Grammar of shame]. Logicheskii analiz yazyka. Yazyki etiki [The Logical analysis of language. The Languages of ethics]. N. D. Arutyunova, T. E. Yanko, N. K. Ryabtseva (Eds.). Moscow, Yazyki russkoi kul'tury Publ., 2000, pp. 216-234. (In Russ.)

Chukovskii K. Lyudi i knigi [People and books]. Moscow, Khudozhestvennaya literatura Publ., 1958. 544 p.

Dal' V.I. Tolkovyi slovar' zhivogo velikorusskogo yazyka [The Explanatory dictionary of the living Great Russian language]. Moscow, Khudozhestvennaya literatura Publ., 1935. Vols. 1-4.

Dal' V. I. Poslovitsy russkogo naroda [Russian folk proverbs]. Moscow, Khudozhestvennaya literatura Publ., 1957. 204 p.

Glovinskaya M.Ya. [Gordyi 'proud']. Apresyan V.Yu., Apresyan Yu.D., Babaeva E.E., Boguslavskaya O.Yu., Galaktionova I. V., Glovinskaya M.Ya., Iomdin B.L., Krylova T. V., Levontina I.B., Lopukhina A. A., Ptentsova A. V., Sannikov A. V., Uryson E.V. Aktivnyi slovar' russkogo yazyka T. 2 [The Active dictionary of the Russian language. Vol. 2]. Yu.D. Apresyan (Ed.). Moscow, Yazyki slavyanskoi kul'tury Publ., 2014, pp. 652-653. (In Russ.)

Hornby A. S., Gatenby E. V., Wakefield H. Advanced learner's dictionary of current English. London, Oxford University Press, 1958. 1528 p.

Macmillan Dictionary. New York, Macmillan Publishing Co., 1973. 1158 p.

Natsional'nyi korpus russkogo yazyka [The National corpus of the Russian language]. Available at: http://ruscorpora.ru

Pavlova A. V. [Author's preface]. Ot lingvistikikmifu: Lingvisticheskaya kul'turologiya $v$ poiskakh «etnicheskoi mental'nosti» [From linguistics to myth: Cultural linguistics in search of an "ethnic mentality"]. I.F. Danilova (Ed.). St Petersburg, Antologiya, 2013, pp. 5-24. (In Russ.)

Sannikov A.V. [The Notions of dignity and humility]. Apresyan V.Yu., Apresyan Yu.D., Babaeva E.E., Boguslavskaya O.Yu., Iomdin B.L., Krylova T.V., Levontina I.B., Sannikov A.V., Uryson E.V. Yazykovaya kartina mira i sistemnaya leksikografiya [The Linguistic worldview and systemic lexicography]. Yu.D. Apresyan (Ed.). Moscow, Yazyki slavyanskoi kul'tury Publ., 2006, pp. 405-468. (In Russ.)

Sannikov A. V. [Gordost' 'pride']. Apresyan V.Yu., Apresyan Yu.D., Babaeva E. E., Boguslavskaya O.Yu., Galaktionova I.V., Glovinskaya M.Ya., Iomdin B.L., Krylova T. V., Levontina I. B., Lopukhina A. A., Ptentsova A. V., Sannikov A. V., Uryson E. V. Aktivnyi slovar' russkogo yazyka T. 2 [The Active dictionary of the Russian language. Vol. 2]. Yu.D. Apresyan (Ed.). Moscow, Yazyki slavyanskoi kul'tury Publ., 2014, pp. 651-652. (In Russ.)

Shmelev A.D. [The Pluralism of ethical systems in the light of linguistic data]. Logicheskii analiz yazyka: Yazyki etiki [The Logical analysis of language. The Languages 
of ethics]. N. D. Arutyunova, T.E. Yanko, N.K. Ryabtseva (Eds.). Moscow, Yazyki russkoi kul'tury Publ., 2000, pp. 380-389. (In Russ.)

Shmelev A.D. [The Russian view of "Western" concepts: linguistic data]. Evolyutsiya ponyatii v svete istorii russkoi kul'tury [The Evolution of notions in the light of the history of Russian culture]. V.M. Zhivov, Yu.V. Kagarlitskii (Eds.). Moscow, Yazyki slavyanskikh kul'tur Publ., 2012, pp. 306-324. (In Russ.)

Shmelev A. D. [Linguistic motifs in Solzhenitsyn's life and literary work: towards the Red Wheel]. Zhizn' i tvorchestvo Aleksandra Solzhenitsyna: na puti k «Krasnomu Kolesu» [The Life and work of Alexander Solzhenitsyn: Towards the Red Wheel]. L. I. Saraskina (Ed.). Moscow, Russkii put' Publ., 2013, pp. 491-496. (In Russ.)

Shmelev A. D. [Pride, Shame and Disgrace in the works of Aleksandr Solzhenitsyn]. Solzhenitsynskie tetradi, 2018, iss. 6, pp. 80-110. (In Russ.)

Tolstaya S. M. [The Russian chest' 'honor' and the Polish honor]. Etnolingwistyka. Problemy języka i kultury, 2013, iss. 25, pp. 9-21. (In Russ.)

Webster's New World dictionary of American English. V.E. Neufeldt (Ed.). $3^{\text {rd }}$ ed. Cleveland, New York, Simon \& Schuster, 1988. 1574 p.

Wierzbicka A. Semantics, Culture, and Cognition. Universal Human Concepts in Culture-Specific Configurations. New York, Oxford University Press, 1992. 487 p. 